\title{
UNILATERAL MEMBRANOUS PULMONARY VENOUS OCCLUSION, PULMONARY HYPERTENSION, AND PATENT DUCTUS ARTERIOSUS
}

\author{
BY \\ D. EMSLIE-SMITH, I. G. W. HILL, AND K. G. LOWE \\ From the Department of Medicine, University of St. Andrews \\ Received August 14, 1954
}

A few patients with patent ductus arteriosus develop cyanosis from intermittent or established shunt-reversal caused by pulmonary hypertension. In these patients the Gibson murmur is absent and clinical and electrocardiographic evidence of right ventricular hypertrophy is found (Cosh, 1953; Hultgren et al., 1953). The pulmonary hypertension can be the result of raised pulmonary vascular resistance, due to persistence of the fœtal pattern of pulmonary arteries and arterioles, to reflex pulmonary vaso-constriction, or to the development of degenerative changes in the pulmonary arterial tree. Increased resistance to blood flow beyond the pulmonary capillaries has not so far been suggested as a possible cause of pulmonary hypertension in patients with patent ductus. The case reported here had a membranous occlusion of the right pulmonary veins, as well as pulmonary arterial hypertension, a patent ductus arteriosus, and central cyanosis. The unilateral pulmonary venous occlusion was responsible for a bizarre and puzzling X-ray picture of the chest. The relationship between the pulmonary venous occlusion, the pulmonary arterial hypertension, and the failure of the ductus arteriosus to close is worthy of consideration.

\section{CASE REPORT}

In June, 1950, a girl, aged 10 years, was referred to one of us (I.G.W.H.) from abroad as a case of cyanotic congenital heart disease. Her parents were healthy and unrelated. Her mother had malaria early in pregnancy. Labour was uneventful. She had one younger brother, aged 7 years, who was healthy.

History. A full-time baby weighing $8 \mathrm{lb}$. she was breast-fed with supplementary feeds for three months, but was difficult to rear and was regarded as a " poor, sickly, little thing." At one year she weighed $16 \mathrm{lb}$., had cut one tooth, and was beginning to toddle. Cyanosis, noted intermittently after the age of two months, was hardly apparent in the second year, but thereafter was nearly always evident and was much worse after exercise. She was never able to play games and would squat after running only about 20 yards, but she learned to ride on horseback. She led a sheltered life at home, taught by her mother, a retired schoolteacher. Her mental development was normal. Her disability did not alter appreciably between the ages of 2 and 10 years, but at the age of 6 to 7 years, she had, in the space of 18 months, three attacks of " pneumonia," in each of which her life hung in the balance.

Examination (June, 1950). She was a slender, high-spirited child, 55 in. tall, and weighing $61 \mathrm{lb}$. Cyanosis of the lips was conspicuous when she had finished undressing but diminished after she had rested on the couch. Clubbing was possibly more marked in fingers than in toes. There was marked sinus arrhythmia. The heart was not enlarged clinically and there was no thrill. There was a loud, widespread systolic murmur, maximal in the pulmonary area, but no diastolic murmur. The femoral pulses were easily palpable.

The blood pressure in the arms was $110 / 80 \mathrm{~mm}$. Hg. Small hæmangiomata on the nape of the neck were the only other abnormality. The hæmoglobin was $15.6 \mathrm{~g}$. $/ 100 \mathrm{ml}$., the red blood cells $5 \cdot 3$ million per c.mm., and the packed cell volume 48 per cent. The brachial arterial oxygen saturation was 82.5 per cent.

The electrocardiogram showed normal rhythm and marked right ventricular hypertrophy. 
Chest X-rays, dating back to 1944 (age 4 years), showed slight generalized cardiac enlargement, a small aortic knob, and prominence of the pulmonary artery segment. The left lung field was normal, but the right showed increased vascularity of unusual pattern (Fig. 1). Bronchoscopy and bronchography showed a normal bronchial tree in each lung.

Subsequent History. She remained well until April, 1953, when she developed a febrile illness diagnosed as "influenza." From that time she became increasingly breathless on exertion and the cyanosis deepened and was less variable. Eventually she was able to walk only 10 to 20 yards. In view of this rapid deterioration she was referred for further investigation.

Examination (November, 1953). Now aged nearly 14 years, she was well-nourished and showed the normal changes of puberty. She was deeply and equally cyanosed in face and extremities. Fingers and toes were equally and grossly clubbed. Apart from constant fine râles at the right lung base, the physical signs were unchanged. The hæmoglobin was $17.1 \mathrm{~g} . / 100 \mathrm{ml}$., the red blood cells 7.6 million per c.mm., and the packed cell volume 66.5 per cent.

The electrocardiogram showed gross right ventricular hypertrophy. Chest X-ray showed more marked changes in the right lung (Fig. 2).

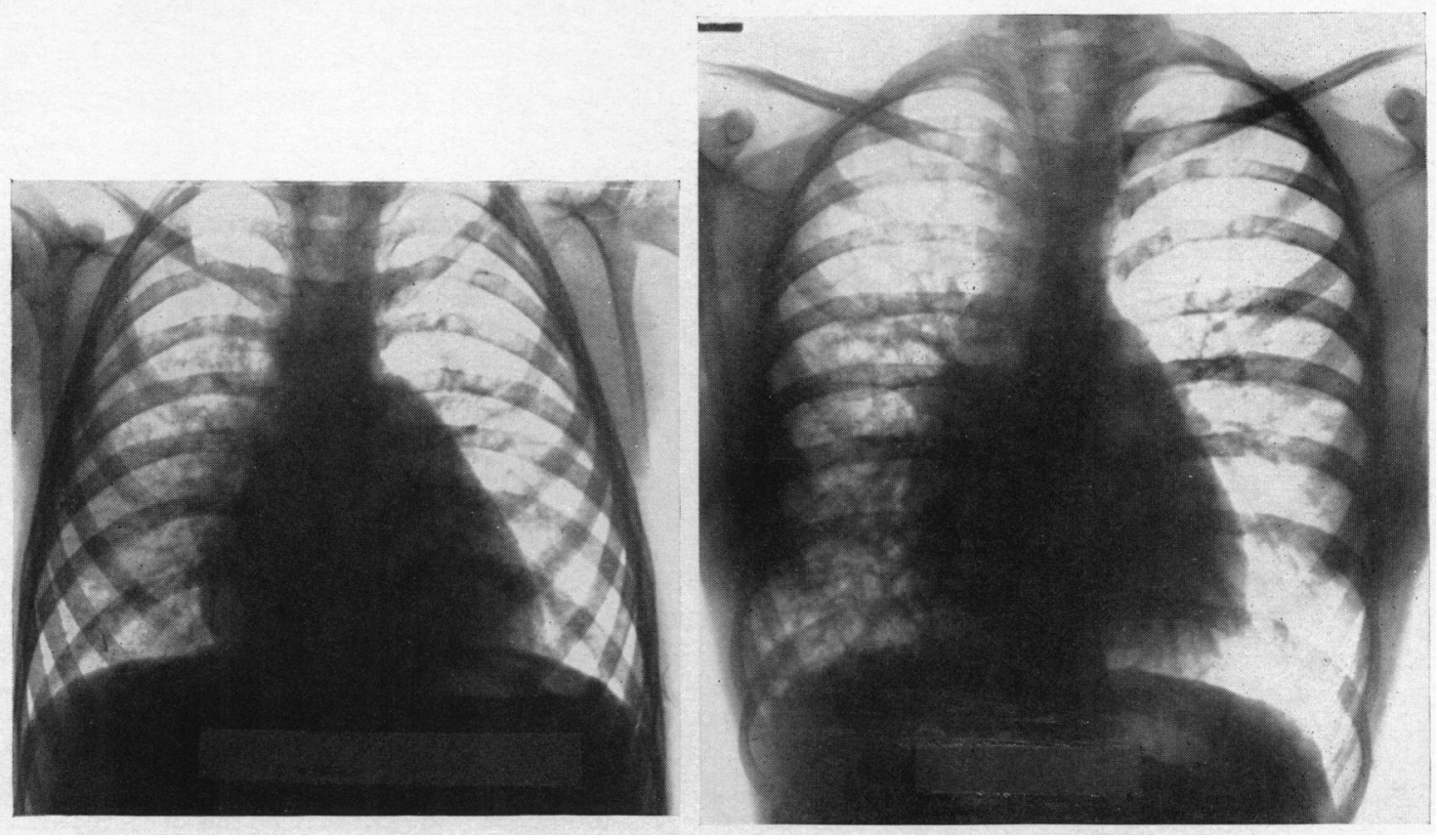

FIG. 1.-Chest X-ray at age of 4 years, showing increased vascular markings in right lung.

FIG. 2.-Chest X-ray at age of 13 years, showing more marked changes in the right lung.

Cardiac Catheterization. The catheter was passed via the right side of the heart into several branches of both right and left pulmonary arteries, and through a patent ductus arteriosus into the descending aorta. The pulmonary arterial and aortic pressures were not measured simultaneously but were of the same order, the mean pressure in the pulmonary arteries being higher than that in the aorta (Fig. 3). The data from catheterization sufficed to make a diagnosis of patent ductus arteriosus with gross pulmonary hypertension; there was suggestive evidence of right-to-left shunt through the ductus. A pulmonary arterial wedge pressure was recorded on the left side but the record was spoilt by artefact. This was not repeated and arterial punctures were not made.

Operation was again considered inadvisable and angiocardiography was therefore not done. The mother was told that the outlook was poor. The girl was allowed home, but became seriously ill with a syncopal attack and intense cyanosis a month later and was re-admitted to hospital next day with fever to $104^{\circ} \mathrm{F}$., pulse rate of 130 a minute, and respiratory rate of 50 a minute. Despite intensive antibiotic therapy and nursing in an oxygen tent, she died on the second day. 


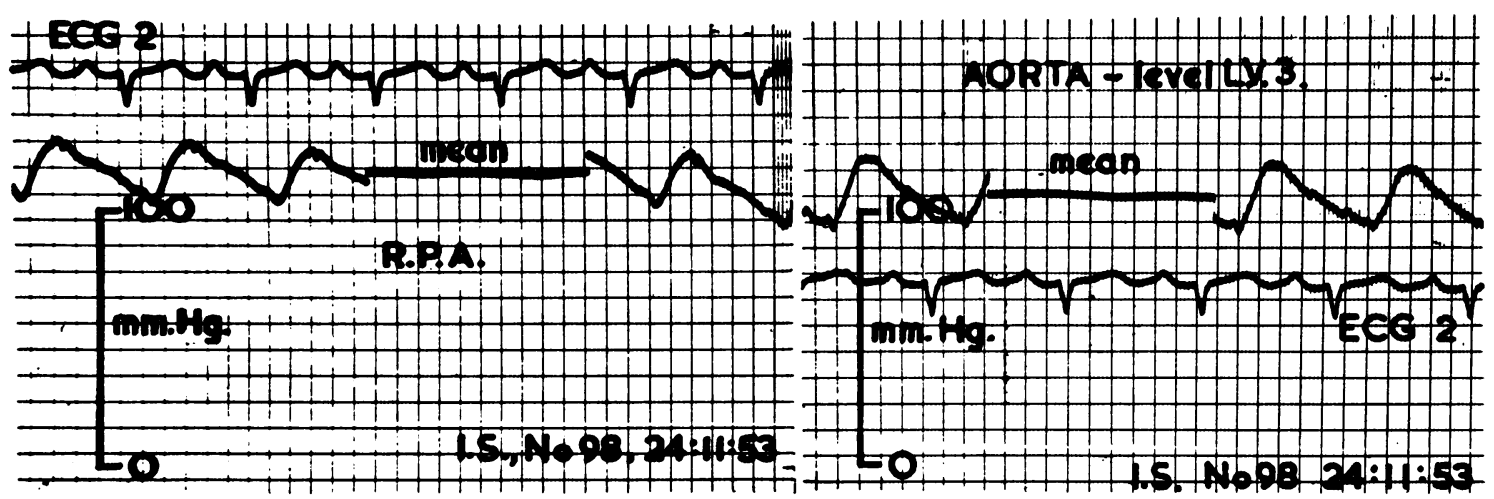

FIG, 3.-Pressure tracings obtained from right main branch of pulmonary artery and abdominal aorta.

Data From Cardiac CATHETERIzation

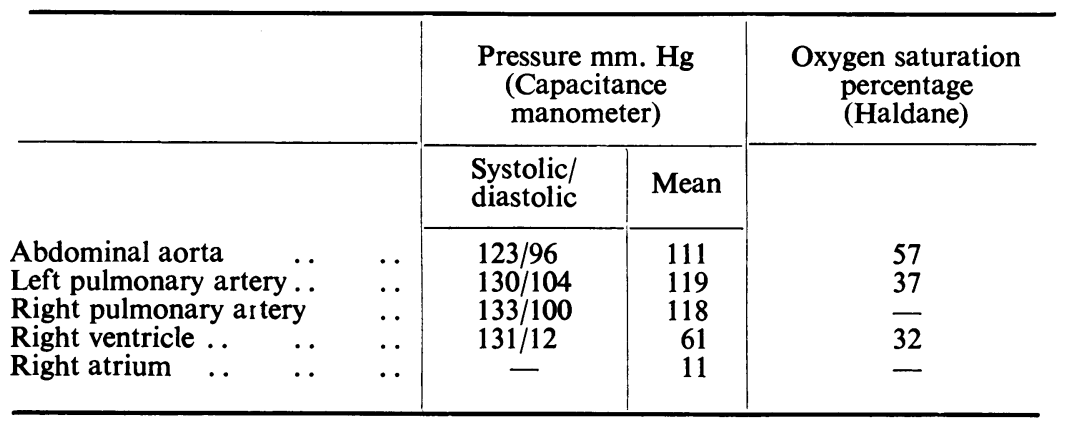

Post-Mortem Findings (Dr. T. Bird)

Patent ductus arteriosus, congenital diaphragm obliterating orifice of right pulmonary vein, gross venous congestion and hamosiderosis of right lung, and endocarditis of tricuspid valve.

Cardiovascular System. The heart was enlarged (320 g.) and globular, the anterior aspect being mainly right atrium and right ventricle (Fig. 4). The right atrium was dilated, with thickened wall, and normal caval entrances. The tricuspid valve showed many opaque white vegetations, up to $4 \mathrm{~mm}$. in diameter, some with a small pedicle, all firmly adherent; otherwise the cusps, chordæ, and papillary muscles were normal. The right ventricle was dilated; the myocardium was thickened, with tiny scattered areas of fibrosis in the posterior wall. The pulmonary artery, arising normally, was dilated (22 mm. diameter). The ductus arteriosus $(10 \mathrm{~mm}$. long and $5 \mathrm{~mm}$. diameter) arose from the origin of the left pulmonary artery; there was slight intimal thickening in the left pulmonary artery opposite the ductus, but not in the aorta. The inter-atrial septum showed no communication. The left atrium was of normal size and thickness. The left pulmonary veins entered normally, with a short common trunk. The right pulmonary veins were of normal diameter, but were felt as hard cords, and appeared to unite just before reaching the atrium. The opening into the atrium of the right upper pulmonary vein was obstructed by a membranous diaphragm containing two tiny openings, situated centrally and inferiorly, and each admitting only a very fine probe (Fig. 5). The lower pulmonary vein ended blindly close by, and did not communicate either with the upper vein or the atrium. The veins contained unorganized clotted blood forming a cast; this extended into the small branches in the lung. The main veins were not dilated, but their walls were two to three times thicker than those of the corresponding veins on the left side. The mitral valve was normal. The left ventricle was dilated and the wall was $10 \mathrm{~mm}$. thick at the base, small patches of fibrosis 


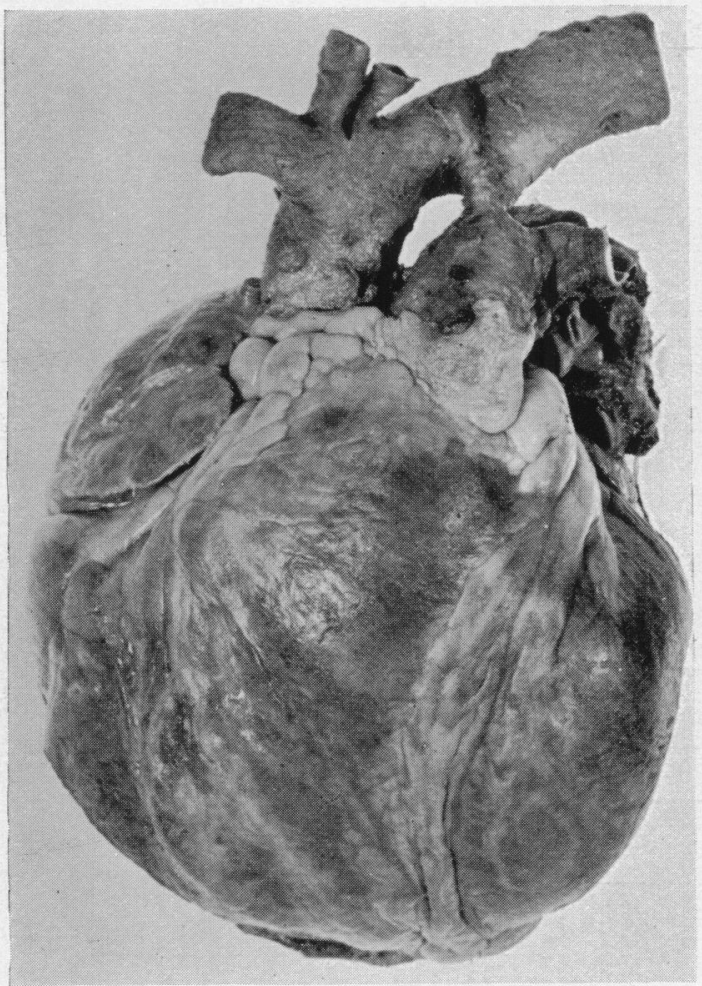

FIG. 4.-Anterior aspect of heart, showing the large right ventricle and ductus arteriosus.

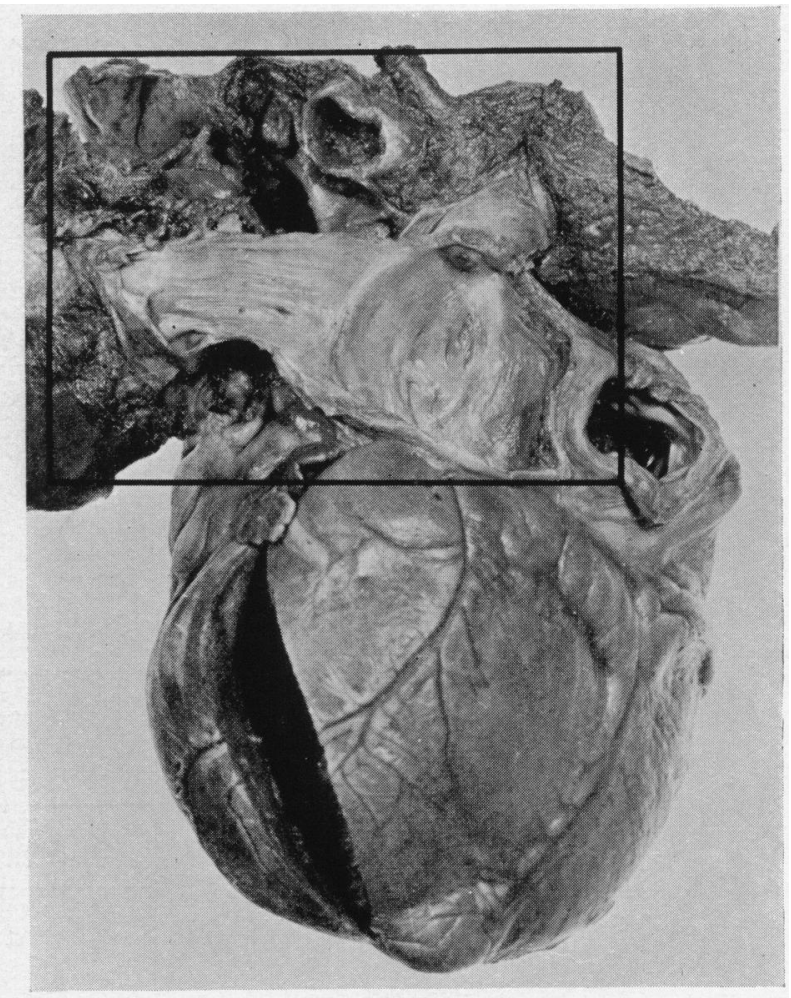

FIG. 5.-View of heart from behind. The posterior wall of the left atrium has been removed.

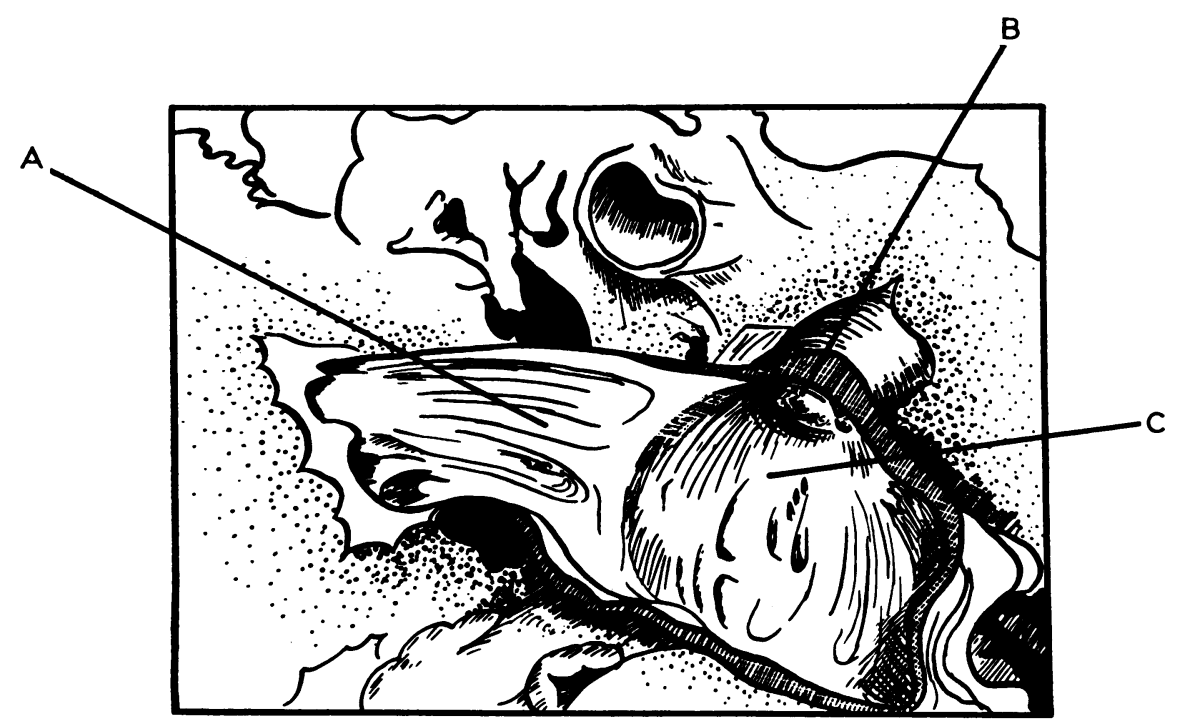

FIG. 6.-Diagram illustrating the anatomy of the area within the rectangle in Fig. 5.

(A) Common trunk of left pulmonary veins laid open.

(B) Central punctum of membrane occluding orifice of upper right pulmonary vein.

(C) Interior of left atrium. 
being seen in the anterior wall near the septum. The coronary arteries were normal. The aorta (10 mm. in diameter at origin), showed a few small intimal fatty plaques in the ascending part.

Respiratory System. The pleural cavities each contained $150 \mathrm{ml}$. of clear yellow fluid; there were no adhesions. The lungs filled the chest and met anteriorly to cover the pericardium. There were striking differences between the two lungs. The left lung showed a normal pleural surface; on section it was dull, dark red with congestion and was moderately œdematous, especially in the lower lobe. The pulmonary artery branches were distinctly atheromatous, the veins normal. There was no evidence of consolidation or infarction, and no visible hæmosiderosis. The right lung was more voluminous. The subpleural venous system, particularly of the lower lobe, was grossly dilated, engorged, and tortuous (Fig. 7). This prominent network of vessels converged posteriorly to form a large leash of veins which passed in the posterior pleural fold to empty into the right azygos venous system. No comparable veins were seen on the left side. Scattered brownish-black spots of hæmosiderosis were visible in the pleura between the distended veins.

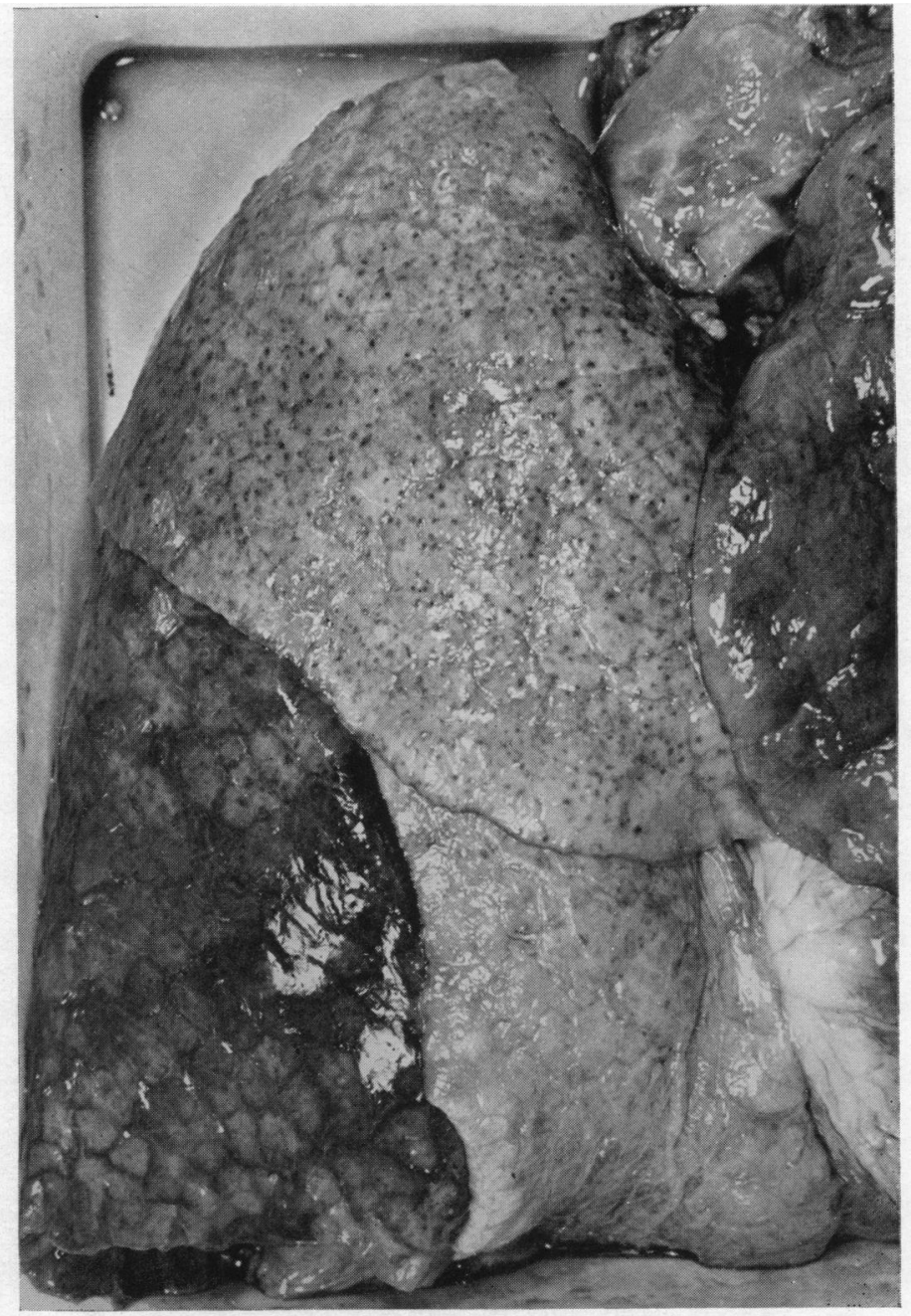

FIG. 7.-Anterior aspect of right lung, showing hæmosiderosis throughout and pleural venous network most marked in lower lobe. 
On section, the right lower lobe was firm, slightly œdematous, and showed obvious foci of hæmosiderosis. The right upper and middle lobes were paler and drier, but of similar consistency; the foci of hæmosiderosis were not so obvious on section as on the pleural surface. No evidence of consolidation or infarction was seen anywhere. All the cut surfaces showed prominent dilated veins, filled with a cast of dark red, clotted blood, without evidence of organization. The pulmonary artery branches were also prominent; all showed atheroma with many raised yellow plaques, but neither calcification nor thrombosis. The bronchi were congested and contained mucopus.

Other organs. The abdominal cavity contained approximately $250 \mathrm{ml}$. of clear yellow fluid. The liver, spleen, and kidneys showed venous congestion. Apart from a thin-walled, simple cyst, $4 \mathrm{~cm}$. in diameter, in the right ovary, the remaining viscera were normal.

\section{Discussion}

Although the diagnosis of patent ductus arteriosus with pulmonary arterial hypertension was made in life, the inequality of the vascular patterns of the lungs was not explained until the venous engorgement and hæmosiderosis of the right lung were revealed post mortem. The pulmonary venous occlusion might have been recognized in life had angiocardiography been justified, and might have been suspected at catheterization if pulmonary arterial wedge pressures had been recorded in both lungs and found to be higher on the right side. This would have indicated right pulmonary venous hypertension since wedge pressures are said to distinguish pulmonary arterial hypertension due to arteriolar resistance from that due to resistance beyond the capillaries (Swan et al., 1954).

Our interpretation of the findings in this case is that the primary abnormality was the membrane that almost completely occluded the right pulmonary veins. This presumably led to right pulmonary venous hypertension and, reflexly, to generalized pulmonary arterial hypertension. As the patient was cyanosed from early infancy we think that a right-to-left shunt through the ductus was present from birth. The pulmonary hypertension may possibly have prevented the ductus from closing. Inadequate oxygen saturation of blood flowing through the left lung may have contributed to the central cyanosis. Blood flowing through the right lung was largely returned to the systemic circuit. The tricuspid endocarditis was thought to be a terminal event; it was certainly of recent origin and had produced no obvious infarctions in either lung. A detailed study of the histology in this case, particularly in relation to the unequally distributed hæmosiderosis, is being made.

\section{SUMMARY}

A 13-year-old girl, handicapped from infancy by breathlessness on exertion, showed cyanosis from the age of two months, a tendency to squat, and, later, obvious digital clubbing. Unequal radiological opacity of the lung fields was present from at least the age of 4 years, the left lung appearing normal and the right lung unduly vascular. Cardiac catheterization demonstrated a patent ductus arteriosus and pulmonary hypertension and suggested right-to-left shunt through the ductus.

Necropsy revealed a congenital membranous occlusion of the right pulmonary veins, hæmosiderosis of the right lung, gross distension of the pleural venous plexus with drainage of the right lung to the systemic veins, right ventricular hypertrophy, and patent ductus arteriosus.

It is suggested that the congenital diaphragm obstructing the venous return from the right lung led to pulmonary arterial hypertension and prevented the ductus arteriosus from closing.

Our thanks are due to Professor A. C. Lendrum of the Department of Pathology, St. Andrews University, for his co-operation, and to Dr. T. Bird for the post-mortem report.

Fig. 2 is from a skiagram sent by Dr. J. G. G. Mitchell. The photographs are by Mr. F. Duncan.

\section{REFERENCES}

Cosh, J. A. (1953). Brit. Heart J., 15, 423.

Hultgren, H., Selzer, A., Pardy, A., Holman, E., and Gerbode, F. (1953). Circulation, 8, 15.

Swan, H. J. C., Zapata-Diaz, J., Burchell, H. B., and Wood, E. H. (1954). Amer. J. Med., $16,12$. 